\title{
OPTIMALISASI MAINTENANCE MENGGUNAKAN SISTEM INSPECTION GRADE PERALATAN KILANG LANGIT BIRU BALONGAN PT PERTAMINA ( PERSERO)
}

\author{
Muhammad Syukron ${ }^{1}$, J.P. Chandra Yoga. ${ }^{2}$ \\ ${ }^{1}$ Program Studi Teknik Metalurgi, Jurusan Teknik Pertambangan, Fakultas Teknologi Mineral \\ Universitas Pembangunan Nasional "Veteran" Yogyakarta \\ Jl. Babarsari 2 Tambakbayan, Yogyakarta \\ E-mail: muhammad.syukron@upnyk.ac.id ${ }^{1}$; cyoga55@gmail.com ${ }^{2}$ \\ $\left(087764977037^{1}, 089605895543^{2}\right)$
}

\section{ABSTRACT \\ MAINTENANCE OPTIMALIZATION USING INSPECTION GRADE SYSTEM FOR PT PERTAMINA ( PERSERO ) BALONGAN LANGIT BIRU EQUIPMENT}

Maintenance of industrial equipment is carried out by conducting periodic inspections of equipment. The results of the inspection will be used as a basis for carrying out maintenance or repairs on the equipment. The equipment that was graded included 31-C-101, 32-C-103, 32-C101.31-V-101, 31-V-104, 32-V-101, and 31-R-101. Inspection grade is determined based on the results of historical analysis of inspection reports on each tool so that it is known when the equipment underwent inspection and what type of inspection was carried out on the equipment. Of the seven equipments that have been graded, the results of the grading of 7 equipments are varied. 6 out of 7 equipment entered grade 2 and there was 1 equipment was in grade 3. Equipment 32-C-103 cannot be predicted damage because the equipment has pitting corrosion and is proven by sudden damage to the equipment. Equipment $31-\mathrm{C}-101$ is the equipment that has the highest corrosion rate among the other 6 equipment that has been graded. (11pt, single line spacing, 1 paragraph).

Keywords: $1^{\text {st }}$ Maintenance; $2^{\text {nd }}$ Inspection; $3^{\text {rd }}$ Damage; $4^{\text {th }}$ Grade; $5^{\text {th }}$ Equipment

\section{ABSTRAK \\ OPTIMALISASI MAINTENANCE MENGGUNAKAN SISTEM INSPECTION GRADE PERALATAN KILANG LANGIT BIRU BALONGAN PT PERTAMINA ( PERSERO )}

Perawatan peralatan pada industri dilakukan dengan melakukan inspeksi pada peralatan secara berkala. Hasil inspeksi akan digunakan sebagai dasar untuk melakukan perawatan ataupun perbaikan pada peralatan. Peralatan yang dilakukan grading antara lain adalah 31-C-101, 32-C103, 32-C-101,31-V-101, 31-V-104, 32-V-101, dan 31-R-101.Grade inspeksi ditentukan berdasarkan hasil analisa sejarah laporan pemeriksaan pada setiap alat sehingga diketahui kapan peralatan tersebut mengalami inspeksi dan isnpeksi jenis apa yang telah dilakukan pada peralatan tersebut. Dari tujuh peralatan yang sudah di grading dihasilkan bervariasi hasil grading dari 7 peralatan. 6 dari 7 peralatan masuk keadalam grade 2 dan ada 1 euipment berada pada grade 3 . Peralatan 32-C-103 tidak bisa dilakukan prediksi kerusakan karena pada peralatan tersebut terdapat localized dan pitting corrosion serta dibuktikan dengan adanya keruskaan secara tiba tiba pada peralatan. Peralatan 31-V-104 merupakan peralatan yang memiliki laju korosi paling tinggi diantara 6 peralatan lainnya yang dilakukan grading.

Kata kunci: $1^{\text {st }}$ Perawatan; $2^{\text {nd }}$ Inspeksi; $3^{\text {rd }}$ Kerusakan; $4^{\text {th }}$ Grade; $5^{\text {th }}$ Peralatan 


\section{Pendahuluan}

PT. Pertamina Refinery Unit VI

Balongan bergerak di bidang pengolahan minyak mentah ( Crude Oil ). PT. Pertamina Refinery Unit VI Balongan merupakan kilang keenam dari tujuh kilang Direktorat Pengolahan PT Pertamina (Persero) dengan kegiatan bisnis utamanya adalah mengolah minyak mentah ( Crude Oil ) menjadi produk produk BBM ( Bahan Bakar Minyak ), non BBM dan Petrokimia.

Unit kerja penulis merupakan unit Naptha Processing Unit ( NPU ). Salah satu seksi unitnya merupakan Unit Naphta Hydrotreating Process ( NHT ) dengan fasilitas kode 31 didesain untuk mengolah Naphta dengan kapasitas 52.000 BPSD atau 345m3/jam.

Pada kegiatan kerja praktek ini penulis mendapatkan peran untuk mengevaluasi beberapa komponen yang digunakan pada PT. Pertamina Refinery Unit VI Balongan. Tujuan dari mengevaluasi komponen ini adalah untuk dilakukan grading atau digolongkan kedalam kelas tertentu sehingga memudahkan untuk melakukan penyusunan maintenanca planning. Kegiatan ini biasa disebut sebagai Grading Equipment, dalam grading equipment ini penulis mengevaluasi suatu equipment berdasarkan laporan pemeriksaan yang dilakukan pada tahun sebelumnya, lalu evaluasi juga didasarkan pada nilai laju korosi yang dihitung berdasarkan data laporan pemeriksaan, setelah itu penulis menganalisa apakah equipment ini bisa diprediksi kerusakannya atau tidak maka bisa disimpulkan equipmen tersebut tergolong kedalam grade tertentu.
Equipment yang dievaluasi antara lain adalah Vessel, Coloum, dan Reaktor dengan kode equipment 31-C101 ,32-C-103, 32-C-101, 31-V-101, 31V-104, 32-V-101， 31-R-101. Setiap masing masing equipment mempunyai history laporan pemeriksaan yang nantinya digunakan sebagai bahan pertimbangan untuk menggolongkan kedalam kelas tertentu.

\section{Metode Penelitian}

Metode penelitian menggunakan data primer hasil dari inspeksi peralatan pada kilang PT Pertamina ( Persero ) Balongan, Indramayu. Data hasil inspeksi selanjutnya di olah dan dikelompokkan per equipment untuk dijadikan dasar penggolongan grade equipment.

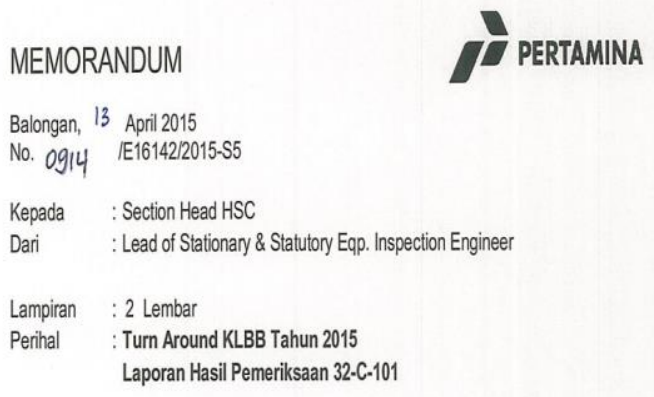

Gambar 1 Dokumen Pemeriksaan Alat

Source : Diambil dari dokumen laporan pemeriksaan equipment PT Pertamina

Data dari hasil inspeksi di analisa kemudian dijadikan bahan pertimbangan untuk menggolongkan equipment PT Pertemina ( Persero ) Unit VI Balongan, Indramayu.

Metode pendekatan yang digunakan pada penelitian ini merupakan pendekatan learning from incident yang dilakukan pada kegiatan 
inspeksi rutin dan inspeksi teknik pada equipment.

Hasil akhir ini berupa Risk Based Inspection yang selanjutnya dilakukan perhitungan resiko berdasarkan prioritas resiko yang terjadi pada equpment yang dilakukan inspeksi.

\section{Hasil dan Pembahasan}

\section{Hasil Inspeksi Equipment 31-C-101}

Tabel 1. Hasil Inspeksi Equipment 31-C-101

\begin{tabular}{|c|c|c|}
\hline \multicolumn{3}{|c|}{$31-C-101$} \\
\hline First Inspection & & Done \\
\hline Internal Insp & & $\begin{array}{c}\text { DONE ( } 28 \text { Maret } \\
2019 \text { ) }\end{array}$ \\
\hline \multicolumn{3}{|l|}{$\mathrm{COI}$} \\
\hline Class & & B1 \\
\hline \multirow[b]{2}{*}{ Corrosion Rate } & $\begin{array}{l}\text { Short } \\
\text { Term }\end{array}$ & 0.28 \\
\hline & Long Term & 0.06 \\
\hline \multirow[b]{4}{*}{ Corr Rate } & Severe & \\
\hline & High & \\
\hline & Normal & LT \& ST \\
\hline & Low & \\
\hline Remaining Life & & RL > 6 Tahun \\
\hline $\begin{array}{c}\text { Predictable } \\
\text { Deteoritation }\end{array}$ & & $Y$ \\
\hline Grade & & 2 \\
\hline \multirow[b]{3}{*}{ Last Insp } & Eksternal & 28-Mar-2019 \\
\hline & Onstream & \\
\hline & Internal & 28-Mar-2019 \\
\hline \multirow[b]{3}{*}{ Next Insp } & Eksternal & 1.5 Year \\
\hline & Onstream & \\
\hline & Internal & 3 Year \\
\hline
\end{tabular}

Source : Data diolah dari dokumen laporan pemeriksaan equipment PT Pertamina

\section{Laporan hasil pemeriksaan} menjelaskan bahwa kondisi equipment telah dilakukan pemeriksaan internal dengan laju korosi short term sebesar
$0.28 \mathrm{~mm} / \mathrm{y}$ dan laju korosi long term sebesar $0.06 \mathrm{~mm} / \mathrm{y}$. Klasifikasi laju korosi pada equipment ini tergolong normal. Meskipun begitu pada equipment ini terdapat pitting corrosion pada internal shell yang didasarkan pada laporan pemeriksaan hasil inspeksi equipment tesebut. Kerusakan itu menjadi hal yang harus diperhatikan sehingga dalam rangka perbaikan selanjutnya harus lakukan pencegahan.

Berdasarkan laporan pemeriksaan equipment ini dapat dilakuakan prediksi kerusakan. Hal ini didasarkan pada laporan equipment pada tahun 2010 yang menjelaskan keadaaan equipment sehingga bisa dilakukan perbaikan lebih lanjut sehingga pada saat laporan pemeriksaan 2015 tidak terdapat kerusakan yang sama

Maka dari itu equipment ini digolongkan pada grade 2 dengan penjelasan tingkat dimana laju kerusakan suatu peralatan dapat diketahui dengan laju kerusakan normal. Pada tingkat ini kerusakan peralatan dapat diketahui bahkan dapat di prediksi sehingga diperlukannya inspeksi secara berkala.

\section{Hasil Inspeksi Equipment 32-C-103}

Equipment ini telah dilakukan internal inspection berdasarkan data laporan pemriksaan. Equipment ini memiliki besaran laju korosi short term sebesar $0.24 \mathrm{~mm} /$ year dan besaran korosi long term sebesar $0.13 \mathrm{~mm} /$ year. Besaran laju korosinya di golongkan pada kategori normal. Pada equipment ini tidak bisa di lakukan prediksi kerusakan. Hal ini didasarkan pada 
Journal Of Metallurgical Engineering And Processing Technology, Vol. 2, No. 2, February 2022, pp. 66-74

P-ISSN: 2723-6854, E-ISSN: 2798-1037

laporan pemeriksaan pada tahun 2014 yaitu terjadi kebocoran pada bagian shell.

Tabel 2. Hasil Inspeksi Equipment $32-\mathrm{C}-103$

\begin{tabular}{|c|c|c|}
\hline \multicolumn{3}{|c|}{$32-C-103$} \\
\hline $\begin{array}{c}\text { First } \\
\text { Inspection }\end{array}$ & & Done \\
\hline Internal Insp & & $\begin{array}{l}\text { DONE ( } 30 \\
\text { Desember } \\
2020 \text { ) }\end{array}$ \\
\hline \multicolumn{3}{|l|}{$\mathrm{COI}$} \\
\hline Class & & B1 \\
\hline \multirow[b]{2}{*}{$\begin{array}{l}\text { Corrosion } \\
\text { Rate }\end{array}$} & $\begin{array}{l}\text { Short } \\
\text { Term }\end{array}$ & 0.24 \\
\hline & $\begin{array}{l}\text { Long } \\
\text { Term }\end{array}$ & 0.13 \\
\hline \multirow[b]{4}{*}{ Corr Rate } & Severe & \\
\hline & High & \\
\hline & Normal & LT \& ST \\
\hline & Low & \\
\hline $\begin{array}{l}\text { Remaining } \\
\text { Life }\end{array}$ & & $\mathrm{RL}>6$ Tahun \\
\hline $\begin{array}{l}\text { Predictable } \\
\text { Deteoritation }\end{array}$ & & $\mathrm{N}$ \\
\hline Grade & & 2 \\
\hline \multirow[b]{3}{*}{ Last Insp } & Eksternal & 30-Dec-2020 \\
\hline & Onstream & \\
\hline & Internal & 30-Dec-2020 \\
\hline \multirow[b]{3}{*}{ Next Insp } & Eksternal & 1.5 Year \\
\hline & Onstream & \\
\hline & Internal & 3 Year \\
\hline
\end{tabular}

Source : Data diolah dari dokumen laporan pemeriksaan equipment PT Pertamina

Pada laporan pemeriksaan tahun 2010 menjelaskan bahwa equipment ini tidak menunjukan kerusakan sehingga tidak diprediksi kebocoran yang terjadi.

Equipment ini digolongkan pada grade 2 dengan remaining life lebih dari 6 tahun.

\section{Hasil Inspeksi Equipment 32-C-101}

Equipment ini telah dilakukan internap inspection pada 13 April 2015. Untuk besaran laju korosi di short term sebesar $0.04 \mathrm{~mm} /$ year pada long term sebesar $0.021 \mathrm{~mm} /$ year. Klasifikasi laju korosi pada equipment ini digolongkan pada kategori low.

Tabel 3. Hasil Inspeksi Equipment 32-C-101

\begin{tabular}{|c|c|c|}
\hline \multicolumn{3}{|c|}{$32-C-101$} \\
\hline $\begin{array}{c}\text { First } \\
\text { Inspection }\end{array}$ & & Done \\
\hline Internal Insp & & $\begin{array}{c}\text { DONE ( } 13 \\
\text { April 2015) }\end{array}$ \\
\hline \multicolumn{3}{|l|}{$\mathrm{COI}$} \\
\hline Class & & B1 \\
\hline \multirow[b]{2}{*}{$\begin{array}{c}\text { Corrosion } \\
\text { Rate }\end{array}$} & $\begin{array}{l}\text { Short } \\
\text { Term }\end{array}$ & 0.04 \\
\hline & $\begin{array}{l}\text { Long } \\
\text { Term }\end{array}$ & 0.021 \\
\hline \multirow[b]{4}{*}{ Corr Rate } & Severe & \\
\hline & High & \\
\hline & Normal & \\
\hline & Low & LT \& ST \\
\hline $\begin{array}{l}\text { Remaining } \\
\text { Life }\end{array}$ & & $\begin{array}{l}\mathrm{RL}>10 \\
\text { Tahun }\end{array}$ \\
\hline $\begin{array}{c}\text { Predictable } \\
\text { Deteoritation }\end{array}$ & & $Y$ \\
\hline Grade & & 3 \\
\hline \multirow[b]{3}{*}{ Last Insp } & Eksternal & 13-Apr-15 \\
\hline & Onstream & \\
\hline & Internal & 13-Apr-15 \\
\hline \multirow[b]{3}{*}{ Next Insp } & Eksternal & 2.5 Year \\
\hline & Onstream & \\
\hline & Internal & 5 Year \\
\hline
\end{tabular}

Source : Data diolah dari dokumen laporan pemeriksaan equipment PT Pertamina

Pada laporan pemeriksaan equipment ini tidak didapati kerusakan pada equipment. Perawatan yang dilakukan hanya perawatan umum 
Journal Of Metallurgical Engineering And Processing Technology, Vol. 2, No. 2, February 2022, pp. 66-74

P-ISSN: 2723-6854, E-ISSN: 2798-1037

seperti membersihkan perawatan dan dilakukan inspeksi rutin.

Equipment ini memiliki remaining life lebih dari 10 tahun. Prediksi kerusakan bisa dilakukan menghasilkan grade 3 .

\section{Hasil Inspeksi Equipment 31-V-101}

Tabel 4. Hasil Inspeksi Equipment 31-V-

101

\begin{tabular}{|c|c|c|}
\hline \multicolumn{3}{|c|}{$31-V-101$} \\
\hline $\begin{array}{c}\text { First } \\
\text { Inspection }\end{array}$ & & Done \\
\hline Internal Insp & & $\begin{array}{c}\text { DONE ( } 13 \text { April } \\
2015 \text { ) }\end{array}$ \\
\hline \multicolumn{3}{|l|}{$\mathrm{COI}$} \\
\hline Class & & B1 \\
\hline \multirow[b]{2}{*}{$\begin{array}{l}\text { Corrosion } \\
\text { Rate }\end{array}$} & $\begin{array}{l}\text { Short } \\
\text { Term }\end{array}$ & 0.26 \\
\hline & $\begin{array}{l}\text { Long } \\
\text { Term }\end{array}$ & 0.25 \\
\hline \multirow[b]{4}{*}{ Corr Rate } & Severe & \\
\hline & High & \\
\hline & Normal & LT \& ST \\
\hline & Low & \\
\hline $\begin{array}{l}\text { Remaining } \\
\text { Life }\end{array}$ & & RL > 6 Tahun \\
\hline $\begin{array}{l}\text { Predictable } \\
\text { Deteoritation }\end{array}$ & & Y \\
\hline Grade & & 2 \\
\hline \multirow[b]{3}{*}{ Last Insp } & Eksternal & 13-Apr-15 \\
\hline & Onstream & \\
\hline & Internal & 13-Apr-15 \\
\hline \multirow[b]{3}{*}{ Next Insp } & Eksternal & 1.5 Year \\
\hline & Onstream & \\
\hline & Internal & 3 Year \\
\hline
\end{tabular}

Source : Data diolah dari dokumen laporan pemeriksaan equipment PT Pertamina

Equipment ini telah dilakukan internal inspection pada tanggal 13 April 2015. Besaran laju korosi pada short term sebesar $0.26 \mathrm{~mm} /$ year dan pada long term sebesar $0.25 \mathrm{~mm} /$ year. Besaran laju korosi ini diklasifikasikan pada klasifikasi normal. Remaining life lebih dari 6 tahun.

Pada equipmet ini bisa dilakukan prediksi kerusakan, hal ini dilihat pada laporan pemeriksaan yang melakukan perbaikan untuk mencegah kerusakan. Maka equipment ini termasuk dalam grade 2 .

\section{Hasil Inspeksi Equipment 31-V-104}

Tabel 5. Hasil Inspeksi Equipment 31-V-

104

\begin{tabular}{|c|c|c|}
\hline \multicolumn{3}{|c|}{$31-V-104$} \\
\hline $\begin{array}{c}\text { First } \\
\text { Inspection }\end{array}$ & & Done \\
\hline Internal Insp & & $\begin{array}{l}\text { DONE ( } 13 \\
\text { April 2015) }\end{array}$ \\
\hline \multicolumn{3}{|l|}{$\mathrm{COI}$} \\
\hline Class & & B1 \\
\hline \multirow[b]{2}{*}{$\begin{array}{l}\text { Corrosion } \\
\text { Rate }\end{array}$} & $\begin{array}{l}\text { Short } \\
\text { Term }\end{array}$ & 0.486 \\
\hline & $\begin{array}{l}\text { Long } \\
\text { Term }\end{array}$ & 0.486 \\
\hline \multirow[b]{4}{*}{ Corr Rate } & Severe & \\
\hline & High & \\
\hline & Normal & LT \& ST \\
\hline & Low & \\
\hline $\begin{array}{l}\text { Remaining } \\
\text { Life }\end{array}$ & & RL > 6 Tahun \\
\hline $\begin{array}{c}\text { Predictable } \\
\text { Deteoritation }\end{array}$ & & $Y$ \\
\hline Grade & & 2 \\
\hline \multirow[b]{3}{*}{ Last Insp } & Eksternal & 13-Apr-15 \\
\hline & Onstream & \\
\hline & Internal & 13-Apr-15 \\
\hline \multirow[b]{3}{*}{ Next Insp } & Eksternal & 1.5 Year \\
\hline & Onstream & \\
\hline & Internal & 3 Year \\
\hline
\end{tabular}

Source : Data diolah dari dokumen laporan pemeriksaan equipment PT Pertamina 
Pada equipment ini telah dilakukan internal inspection pada tanggal 13 April 2015. Hasil inspeksi didapatkan besaran laju korosi short term $0.486 \mathrm{~mm} /$ year dan long term 0.486 $\mathrm{mm} /$ year. Besaran laju korosi ini diklasifikasikan pada klasifikasi normal dengan remaining life lebih dari 6 tahun.

Equipment ini bisa dilakukan prediksi kerusakan yang didasarkan pada laporan pemeriksaan. Maka equipment ini digolongkan pada grade 2

\section{Hasil Inspeksi Equipment 32-V-101}

Tabel 6. Hasil Inspeksi Equipment 32-V-

101

\begin{tabular}{|c|c|c|}
\hline \multicolumn{3}{|c|}{$32-V-101$} \\
\hline $\begin{array}{c}\text { First } \\
\text { Inspection }\end{array}$ & & Done \\
\hline Internal Insp & & $\begin{array}{c}\text { DONE ( } 10 \\
\text { Agustus } 2020 \\
\text { ) }\end{array}$ \\
\hline \multicolumn{3}{|l|}{$\mathrm{COI}$} \\
\hline Class & & B1 \\
\hline \multirow[b]{2}{*}{$\begin{array}{c}\text { Corrosion } \\
\text { Rate }\end{array}$} & $\begin{array}{l}\text { Short } \\
\text { Term }\end{array}$ & 0.12 \\
\hline & $\begin{array}{l}\text { Long } \\
\text { Term }\end{array}$ & 0.073 \\
\hline \multirow[b]{4}{*}{ Corr Rate } & Severe & \\
\hline & High & \\
\hline & Normal & LT \& ST \\
\hline & Low & \\
\hline $\begin{array}{l}\text { Remaining } \\
\text { Life }\end{array}$ & & RL > 6 Tahun \\
\hline $\begin{array}{l}\text { Predictable } \\
\text { Deteoritation }\end{array}$ & & $Y$ \\
\hline Grade & & 2 \\
\hline \multirow[b]{3}{*}{ Last Insp } & Eksternal & 10-Aug-20 \\
\hline & Onstream & \\
\hline & Internal & 10-Aug-20 \\
\hline \multirow[b]{3}{*}{ Next Insp } & Eksternal & 1.5 Year \\
\hline & Onstream & \\
\hline & Internal & 3 Year \\
\hline
\end{tabular}

Source : Data diolah dari dokumen laporan pemeriksaan equipment PT Pertamina

Pada equipment ini telah dilakukan internal inspection pada tanggal 10 Agustus 2020. Besaran laju korosi pada short term sebesar 0.12 dan long term 0.073. Besaran laju korosi pada equipment ini diklasifikasikan pada klasifikasi normal. Remaining life diasumsikan lebih dari 6 tahun dan equipment ini bisa dilakukan prediksi kerusakan.

Hasil laporan pemeriksaan tidak menunjukan adanya kerusakan serius pada equipment ini. Namun ada beberapa bagian yang harus dilakukan pergantian seperti demister. Maka dari itu equipment ini digolongkan dalam grade 2 .

\section{Hasil Inspeksi Equipment 31-R-101}

Equipment ini merupakan jenis strat up yang beroperasi pada 15 Februari 2021 dan belum didapatkan data inspeksi terbaru mengenai equipment ini sehingga data yang digunakan merupakan data pabrikan dari pembuat equipment.

Inspeksi terakhir dilaksanakan pada 13 April 2015 dan sudah dilakukan internal inspection. Besaran laju korosi pada short term dan long term masih sama menggunakan standar pabrikan equipment yaitu sebesar 0.051. Besaran laju korosi ini diklasifikasikan dalam klasifikasi normal.

Equipment ini memiliki remaining life lebih dari 6 tahun . 
Tabel 7. Hasil Inspeksi Equipment 31-R-

101

\begin{tabular}{|c|c|c|}
\hline \multicolumn{3}{|c|}{$31-C-101$} \\
\hline $\begin{array}{c}\text { First } \\
\text { Inspection }\end{array}$ & & Done \\
\hline Internal Insp & & $\begin{array}{l}\text { DONE ( } 13 \\
\text { April 2015) }\end{array}$ \\
\hline \multicolumn{3}{|l|}{$\mathrm{COI}$} \\
\hline Class & & B1 \\
\hline \multirow[b]{2}{*}{$\begin{array}{l}\text { Corrosion } \\
\text { Rate }\end{array}$} & $\begin{array}{l}\text { Short } \\
\text { Term }\end{array}$ & 0.051 \\
\hline & $\begin{array}{l}\text { Long } \\
\text { Term }\end{array}$ & 0.051 \\
\hline \multirow[b]{4}{*}{ Corr Rate } & Severe & \\
\hline & High & \\
\hline & Normal & LT \& ST \\
\hline & Low & \\
\hline $\begin{array}{l}\text { Remaining } \\
\text { Life }\end{array}$ & & $\mathrm{RL}>6$ Tahun \\
\hline $\begin{array}{c}\text { Predictable } \\
\text { Deteoritation }\end{array}$ & & $Y$ \\
\hline Grade & & 2 \\
\hline \multirow[b]{3}{*}{ Last Insp } & Eksternal & 13-Apr-15 \\
\hline & Onstream & \\
\hline & Internal & 13-Apr-15 \\
\hline \multirow[b]{3}{*}{ Next Insp } & Eksternal & 1.5 Year \\
\hline & Onstream & \\
\hline & Internal & 3 Year \\
\hline
\end{tabular}

Source : Data diolah dari dokumen laporan pemeriksaan equipment PT Pertamina

Predictable deteoritaion pada equiment ini dikategorikan "Y" artinya equipment ini bisa diprediksi jenis kerusakannya sehingga bisa ditanggulangi. Maka equipment ini masuk ke dalam grade 2 .

\section{Pengaruh Sistem Grading Terhadap Optimalisasi Maintenance}

Sistem grading pada peralatan dapat membantu optimaliasasi maintenance. Pada tabel tersbeut ada penjelasan bahwa last inspection dan next inspection. Dapat dikatakan bahwa setiap peralatan memiliki waktu next inspection yang hampir sama karena memiliki grade yang sama pula. Namun pada peralatan 32-C-103 tidak bisa diprediksi tingkat kerusakan yang datang dikarenakan peralatan tersebut sudah pernah terjadi kebocoran. Pada equipment 32 -C-103 juga didapati localized corriosion, hal ini dibuktikan dengan adany kebocoran pada satu bagian tertentu sementara bagian lainnya masih baik. Dari hasil itu maka bisa dievaluasi euipment 32-C-103 ini diperlukan perhatian khusus. Maka dari itu inspection secara teliti harus dilakukan pada peralatan ini.

Sistem grading juga menjelaskan grade dari peralatan yang artinya jika berada di grade 2 maka peralatn tersebut bisa diprediksi kerusakannya, memiliki laju korosi yang kecil dan bisa diprediksi kerusakannya. Maka bisa dikatakan 6 dari 7 peralatan diatas yang berada di grade 2 bisa diprediksi tingkat kerusakannya dengan melakukan inspeksi secara berkala yang sudah direkomendasikan berdasarpak SEP KP 52.

$$
\text { Pada peralatan 32-C-101 }
$$
digolongkan sebagai grade 3 karena memiliki laju korosi yang sangat kecil, kerusakan terhadap peralatan bisa diprediksi dan memunyai remaining life yang tinggi maka bisa dikatakan 
peralatan ini aman dengan inspeksi secara berkala den memiliki resiko kerusakan paling rendah dibandingkan 6 peralatan lainnya yang berada pada grade 2. Namun begitu peralatan pada grade 3 tidak menurunkan prioritas inspeksi karena inspeksi pada setiap peralatan telah diatur dalam SEP KP 52 sehingga wajib untuk dilakukan inspeksi secara berkala.

\section{Pengaruh Besaran Laju Korosi Terhadap Optimalisasi Maintenance}

Besaran laju korosi terbesar berada pada peralatan $31-\mathrm{V}-104$. Besaran laju korosi pada peralatan ini mencapai $0.486 \mathrm{~mm} / \mathrm{y}$ dengan kategori laju korosi yang normal. Walaupun begitu besaran laju korosinya hampir mendekati kategori High ( >0.51). Besaran laju korosi pada peralatan 31-V104 ini bisa dijadikan sebagai dasar untuk inspeksi peralatan. Dibutuhkan inspeksi teliti lebih lanjut mengenai laju korosi pada peralatan 31-V-104 ini untuk mengajukan rekomendasi perawatan peralatan. Ketika dilihat dari nilai laju korosi yang tinggi, solusi yang dimugkinkan untuk dilakukan adalah perawatan coating dan evaluasi pemilihan material berdasarkan kandungan logam pada peralatan $31-\mathrm{V}$ 104.

Peralatan 31-V-104 ini tergolong dalam grade 2. Meskipun tergolong sebagai grade 2 namun angka besaran laju korosi yang terjadi pada peralatan ini perlu diperhatikan. Laju korosi yang semakin tinggi akan memperpendek umur peralatan sehingga diperlukan penggantian peralatan yang akan memakan biaya.

\section{Kesimpulan}

Berdasarkan hasil analisa hasil inspeksi pada 7 equipment PT Pertamina RU Unit VI Kilang Biru Balongan maka didapati kesimpulan:

1. Hasil inspectin grade pada 7 peralatan yang didasarkan pada histrory inspection, class, corrosion rates, remaining life dan predictable deteoritation menghasilkan 6 peralatan berada pada grade 2 dan satu peralatan pada grade 3. Peralatan 31-C-101 di grade 2, peralatan 32-C-103 di grade 2, peralatan 32-C-101 di grade 3, peralatan $31-\mathrm{V}-101$ di grade 2 , peralatan $31-\mathrm{V}-104$ di grade 2, peralatan 32-V-101 di grade 2 , dan peralatan 31-R-101 di grade 2 .

2. Pada peralatan 32-C-103 tidak dapat di prediksi kerusakannya karena memiliki riwayat mengalami kebocoran pada bagian shell sehingga wajib dilakukan inspeksi teliti secara berkala.

3. Pada peralatan 31-V-104 didapati besaran laju korosi yang paling tinggi diantara 6 peralatan lainnya. Hal ini membuat umur peralatan menjadi pendek. Besarnya angka laju korosi pada peralatan ini maka wajib dilakukan inspeksi teliti secara berkala dan dilakukan evaluasi pemilihan material yang didasarkan pada damage mechanism. 
Saran

1. Hasil inspection grade merupakan hasil yang didasari pada history laporan pemeriksaan sehingga tidak menutup kemungkinan akan terjadi perubahan grade pada peralatan seiring berjalannya waktu. Maka dari itu perlu dilakukannya grading peralatan secara berkala agar bisa menyesauaikan dengan perkembangan laporan pemeriksaan peralatan.

2. Angka besaran laju korosi terbesar ada pada peralatan 31-V-104. Maka dari itu sebaiknya dilakukan analisa damage mechanism pada peralatan ini sehingga bisa dijadikan dasar untuk melakukan pemilihan material peralatan yang lebih tahan korosi.

3. Walaupun peralatan 32-C-103 tidak dapat di prediksi kerusakannya akibat laporan kebocoran akan tetapi perlu adanya pembaharuan laporan pemeriksaan yang baru sehingga history peralatannya bisa terlihat bahwa peralatan ini bisa diprediksi tingkat kerusakannya karena sudah dilakukan penggantian peralatan.

\section{Daftar Pustaka}

\section{Book chapter}

1. KHolis, Ikhsan, 2016, Program Inspeksi Industri Migas dan Jenis-Jenis Peralatan Industri Migas dan Inspeksi Peralatan, Cepu, Pusdiklat Migas
2. Standart Enjiniring Pertamina. 1997. Inspeksi Dan Pengujian Pabrik Dalam Keadaan Beroperasi.

3. American Petroleum Institute. 2008. Risk-Based Inspection Technology, API Standard 581,Second Edition. Washington D.C

\section{Journal article}

1. Memorandum. 2019. Laporan Stop NPU Maret 2019 Hasil Pemeriksaan 31-C-101. Indramayu

2. Memorandum. 2015. Turn Around KLBB Tahun 2015 Hasil Pemeriksaan 32-C101.Indramayu

3. Memorandum. 2020. Hasil Pemeriksaan Dan Rekomendasi Perbaikan 32$C$-103. Indramayu

4. Memorandum. 2015. Laporan Hasil Pemeriksaan Oxygen Stripper Receiver 31-V-101. Indramayu

5. Memorandum. 2015. Turn Around KLBB Laporan Final Hasil Pemeriksaan dan Perbaikan 31-V-104. Indramayu

6. Memorandum. 2020. Laporan Stop NPU 2020 Hasil Pemeriksaan 32-V-101 Separator. Indramayu

7. Memorandum. 2015. Laporan Hasil Pemeriksaan Reactor 31$R$-101. Indramayu. 